\title{
All change at the GDC?
}

\section{The intention is for these changes}

to mean more than just a reduction in size of the GDC, in other words this is not just a 'downsizing' with business as usual.
Mike Grace m.grace.bdj@bda-dentistry.org.uk tis often stated that the common perception among dentists of the General Dental Council is that it "is there to take my money and strike dentists off the register!". Awareness of the Council's role in protecting the public through setting standards for education of the profession is also increasing with the introduction of Lifelong Learning and Continuing Professional Development (CPD) and now over a third of the profession have signed up to the voluntary recertification scheme, which is most encouraging when considering the commitment of dentists to self regulation.

However, recent events are proving that the GDC is undergoing one of its most significant developments so far, and these changes will certainly alter the above perception of its role. By the end of July this year it is anticipated that there will be an amendment to the Dentists Act of 1984 by an Order under Section 60 of the Health Act 1999 which will seriously alter the Council's size and composition and before the end of the year we should see a second Order which will affect how the Council carries out its regulatory business.

On 9th February this year the GDC held a special meeting to decide on the proposals the Council would make to enable it to participate in its own future, but we must remember that, at this stage, these are only proposals and that the final decision will come from Government. There are two main strands to these proposals, the first affecting the size and composition of Council and the second affecting the the Council's role in monitoring the behaviour of all those on the register, whether dentists or, increasingly in the future, professions complementary to dentistry (PCDs).

The first of these, the composition of the Council and how members of the new Council are chosen, has been the subject of much debate over the last few months. At the February meeting the Council agreed that the small strategic Council should consist of registered dentists, lay members and registered (currently enrolled) PCDs. Registered dentists should form an overall majority of one, and the PCDs should include one hygienist and one dental therapist, although this will be reviewed prior to the registration of new classes of PCDs. The four UK chief dental officers will become associate members of the Council.

With regard to the Council's regulatory role, a Fitness to Practise Panel will be appointed, made up of a fairly substantial number of people who would be available to serve as required (the figure being quoted at the moment is around 100 members). The lay members of this panel would also be chosen by the Queen, but the professional members would be appointed rather than elected, and the exact mechanism for this is still to be decided.

These are the main changes, and the transition from the existing structure to the new one will take place over the next two years, requiring elections for the GDC to take place this October with the members serving under existing arrangements for at least a year until the new arrangements are in place and the new electoral process takes over.

The President of the GDC, Professor Nairn Wilson, has made it clear that the changes are an opportunity for the Council to be more strategic and better able to involve more of the profession in the regulation of dentistry. If he is right then we should be seeing some fairly dramatic changes as a result of the new legislation, hopefully changes that will increase public confidence in dentistry and also close some of the perceived 'distance' between the GDC itself and the majority of dentists. As with so many things, time alone will tell. 